well account for the phonocardiographic features of extreme variability of the $\mathrm{A}_{2}-\mathrm{OC}$ interval and the intermittent absence of the OC. The systolic murmur was in keeping with mitral reflux with its rate related variability.

In a very ill patient with a malfunctioning mitral Starr-Edwards prosthesis we feel that the phonocardiographic findings can be a useful bedside adjunct to the physician and the cardiac surgeon in the assessment of prosthetic function when other methods may not be practicable.

\section{Acknowledgment}

We wish to thank Mr B. B. Milstein for his help and permission to publish this case.

\section{References}

Hultgren, H.N. \& Hubis, H. (1965) A phonocardiographic study of patients with Starr-Edwards mitral prosthesis. American Heart Journal, 69, 306.

LEAChman, R.D. \& Cokkinos, D.V.P. (1969) Absence of the opening click in dehiscence of mitral valve prosthesis. New England Journal of Medicine, 281, 461.

Lee, S.J.K., Zaragoza, A.J., Callaghan, J.C., Couves, C.M. \& STERNS, L.P. (1970) Malfunctioning of the mitral prosthesis (Cutter-Smeloff); clinical and hemodynamic changes in three cases. Circulation, 91, 479.

Spencer, F.C., Trimble, J.K. \& Reeves, R.T. (1965) Successful replacement of a thrombosed mitral ball-valve prosthesis. Journal of the American Medical Association, 194, 11.

Postgraduate Medical Journal (October 1975) 51, 733-734.

\title{
Peripheral gangrene in polycythaemia vera
}

\author{
Paul Gétaz \\ M.B., M.R.C.P. \\ A case of peripheral vascular disease which became \\ gangrenous and led to a diagnosis of polycythaemia \\ vera is described. Chemotherapy has been successful \\ and surgical intervention avoided. The authors stress \\ the importance of full haematological examination of \\ any patient presenting with peripheral digital gangrene.
}

\author{
Peter JaCOBS \\ M.D., Ph.D., F.C.P., M.R.C.Path.
}

\section{Introduction}

Vascular complications in patients with the myeloproliferative syndrome are common, but it is rare for digital ischaemia to be the presenting feature. It is the purpose of the authors to report such a case, to draw attention to the response to therapy, and to emphasize some of the surgical hazards in patients with this condition.

\section{Case report}

A 45-year-old Caucasian female first presented at the age of 36 with peripheral vascular disease. Her haemoglobin was $16 \mathrm{~g} / 100 \mathrm{ml}$, WBC $15,100 / \mathrm{mm}^{3}$ and platelets $430,000 / \mathrm{mm}^{3}$. Bilateral lumbar sym- pathectomy provided symptomatic relief until the age of 43 when she presented with a similar 8-month history of pain and colour changes aggravated by the cold. Haemoglobin was $17 \cdot 7 \mathrm{~g} / 100 \mathrm{ml}$, PCV $53.8 \%$ and WBC $14,900 / \mathrm{mm}^{3}$. Response to Rheomacrodex was complete.

Two years later she was admitted with early gangrene of the right little toe, and both liver and spleen were palpable $4 \mathrm{~cm}$ below the costal margins. Haematology was essentially unchanged. Rheomacrodex led to improvement, but 2 months later she was re-admitted with extensive dry gangrene of the toe. Haemoglobin was $16.6 \mathrm{~g} / 100 \mathrm{ml}$, PCV $48.4 \%$, WBC $23,900 / \mathrm{mm}^{3}$, and platelets $625,000 / \mathrm{mm}^{3}$. Bone marrow aspiration and trephine biopsy confirmed the presence of myelofibrosis. She was started on chlorambucil $8 \mathrm{mg}$ and aspirin $300 \mathrm{mg}$ daily with venesection as required to maintain her PCV at $40-45 \%$. On this regime her haemoglobin and platelets have fallen, and the white count decreased to just above the upper limit of normal. Surgical intervention has been avoided, and her toe has healed progressively. 


\section{Discussion}

Untreated polycythaemia vera carries a high risk of intravascular thrombosis. In a recent review of 200 cases, Barabas, Offen and Meinhard (1973) noted that $49 \%$ presented with vascular complications. These were arterial in $34 \%$, venous in $28 \%$ and both arterial and venous in $13 \%$. Cerebrovascular accidents, preceded in $66 \%$ of the cases by transient ischaemic attacks (TIAs) and digital artery occlusions were the most frequent complications, although presentation with peripheral gangrene has been reported only rarely. In five of fifteen of their cases where only digital arteries were affected, femoral arteriograms showed localized narrowing in femoral or popliteal vessels. In all six patients reported by Gillespie (1973), co-incident atherosclerosis was present, and our patient had clinical evidence of vascular disease. It has been postulated that an underlying vascular abnormality may be a prerequisite for the development of peripheral vascular disease in patients with polycythaemia, and Barabas et al. (1973) feel that in some, if not all, embolism rather than local thrombosis is the mechanism of occlusion. These workers made the observation that in their series cerebrovascular accidents were four times more common than coronary artery disease while the reverse is generally true in arteriosclerosis, and drew a parallel with transient ischaemic cerebral attacks which have been shown to be due to microemboli.

The diagnosis of polycythaemia vera was not difficult in our patient, but where doubt exists, blood volume and red cell mass should be measured by standard radio-isotopic techniques.

The patient with a myeloproliferative syndrome offers particular problems at the time of surgery (Gilbert, 1973) and surgical intervention should be preceded by adequate control of the haematology as these patients are liable to bleeding or thrombotic manifestations. Failure of haemostasis may be seen in spite of a normal or even elevated platelet count, as myeloproliferative platelets are often qualitatively defective. It is recommended that no elective procedure be undertaken unless the patient has been haematologically stable for at least 4 months as they have been shown to have the most favourable postoperative course.

It should be emphasized that hypertonic solutions in the concentrations used for angiography may

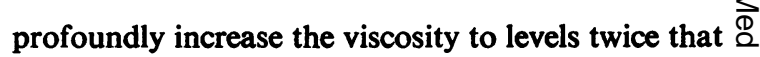
suggested by the PCV, and patients undergoing this $ᄃ$ procedure should be venesected to reduce the PCV (La Celle and Weed, 1971).

Therapy of the underlying haematological condition is probably the most important therapeutic manoeuvre. It must be remembered that thrombocythaemia may be part of the syndrome and that 0 reactive thrombocytosis is a normal response to $\%$ bleeding. Fortunately, platelet function may be $\vec{\circ}$ ablated by a number of agents, of which aspirin and dipyridamole are the two most commonly employed. Venesection should be employed as required to $\frac{}{0}$ maintain the PCV in the range of $40-45 \%$, and chlorambucil is extremely effective in controlling the elevated platelet count. In those patients reported by $\stackrel{G}{-}$ Gillespie (1973), four did extremely well after 8 chemical sympathectomy using phenol, but the two patients in whom sympathectomy was not performed $\omega$ did as well on treatment of the haematological ${ }_{0}$ condition alone. Our patient responded excellently to the above therapy, and the gangrene has disappeared.

In the series of Barabas et al. (1973), ten patients $\frac{0}{0}$ had digital amputations before the diagnosis of $\frac{\mathbb{}}{\square}$ polycythaemia vera was established. It is emphasize $\overrightarrow{0}$ that in any patient presenting with peripheral digitộ gangrene, a full haematological work-up is mand tory, including marrow aspiration and marrow biopsy, and in the event of any suggestion of abnormality, radioisotopic investigations should be performed.

\section{Acknowledgments}

We would like to express our thanks to Dr J. G. Burger, Medical Superintendent, Groote Schuur Hospital, for per- $\frac{7}{0}$ mission to publish this case.

\section{References}

Barabas, A.P., Offen, D.N. \& Meinhard, E.A. (1973) The arterial complications of polycythaemia vera. British
Journal of Surgery, 60, 183 .

GillesPIE, G. (1973) Peripheral gangrene as the presentation of myeloproliferative disorders. British Journal of Surgery, $60,377$.

GILBERT, H.S. (1973) The spectrum of myeloproliferative $\frac{7}{O}$ disorders. Medical Clinics of North America, 57, 355.

LA Celle, P.L. \& WeEd, R.I. (1971) The contribution of $N$ normal and pathologic erythrocytes to blood rheology. In: Progress in Hematology, Vol. VII (Ed. by E. G.N Brown and C. V. Moore). Grune and Stratton, New York. 이 